\title{
Structural and Ionic Conductivity Studies on Nanochitosan Incorporated Polymer Electrolytes for Rechargeable Magnesium Batteries
}

\author{
N. AMMAKUTTI @ SRIDEVI, K.KARUPPASAMY, \\ S.BALAKUMAR and X.SAHAYA SHAJAN*
}

Centre for Scientific and Applied Research (CSAR), School of Basic Engineering and Science (SOBES), PSN College of Engineering and Technology, Tirunelveli- 627 152, Tamilnadu, India

shajan89@gmail.com

Received 22 May 2012 / Accepted 13 June 2012

\begin{abstract}
A series of different composition ratio of polymer electrolytes based on poly (ethylene oxide) $\mathrm{PEO}$ as host polymer, magnesium triflate $\mathrm{Mg}\left(\mathrm{CF}_{3} \mathrm{SO}_{3}\right)_{2}$ as salt and nanochitosan as filler was produced using hot press technique. The complexation of composite polymer electrolyte was confirmed by FTIR. The nanocomposite polymer electrolyte exhibited highest ionic conductivity in the order of $3.41 \times 10^{-3.1} \mathrm{~S} / \mathrm{cm}$ at $60{ }^{\circ} \mathrm{C}$ and showed the dependence of the dissolved magnesium salt and nanofiller. The structural and conformational changes in the polymer host due to entrapment of nanoparticles in the filler and ion-polymer interaction were investigated by SEM method. The DSC results show the role of filler in de-linking the cross linked polymer chains and thereby increasing the ionic conductivity.
\end{abstract}

Keywords: Nanocomposite solid polymer electrolyte, Magnesium battery, Nanochitosan

\section{Introduction}

Composite polymer electrolytes obtained by the complexation with different metal salts has emerged as the key concept of academic and industrial area due to their high energy density, volumetric stability, electrochemical stability ${ }^{1}$ and good interfacial contact with electrode materials. Investigations on rechargeable magnesium batteries show accountable comparison with lithium batteries. The closeness in the ionic radii of $\mathrm{Li}^{+}$and $\mathrm{Mg}^{2+}$ ions helps in replacing them in insertion compounds ${ }^{2}$. Safe handling of $\mathrm{Mg}$ metal in oxygen and humid atmosphere is more stable than lithium which requires an argon or helium atmosphere where safety problem arises. There have been some publications on the complexes of PEO with magnesium salt so far. PEO's unusual mechanism of ionic transport, its ability to form dimensionally stable film thin film of solid polymer electrolyte has been widely studied for potential applications in solid state batteries and other electrochemical devices ${ }^{3}$. PEO forms ion - conductive complexes, with salts of mono-, di- or trivalent metals. Ionic conductivities 
ranging from $10^{-8}$ to $10^{-5} \mathrm{~S} / \mathrm{cm}$ were reported for those complexes ${ }^{4}$. However, the transference number is lower due to the strong coordination of ions with the oxygen atoms of PEO. The enhancement of ionic conductivity in a composite polymer matrix is eluded by incorporating nanosized fillers, since the dispersed filler particle size plays a major role in controlling the electrochemical properties of polymer electrolyte. The incorporation of nanosized fillers such as $\mathrm{SiO}_{2}, \mathrm{Al}_{2} \mathrm{O}_{3}, \mathrm{ZrO}_{2}$ and $\mathrm{CeO} 2$ in the polymer matrix has been reported in the literature ${ }^{5-7}$. In the present work naturally abundant ${ }^{8}$ and renewable biopolymer chitosan is used as filler which increases the ionic conductivity due to chelation of transitional metal ions ${ }^{9,10}$ and improves thermal stability. The nanocomposite polymer membranes were prepared and they were examined to note the effect of nanochitosan addition into the complex of PEO-Mg $\left(\mathrm{CF}_{3} \mathrm{SO}_{3}\right)_{2}$ via FTIR, ionic conductivity and thermal studies.

\section{Experimental}

The host polymer PEO (Sigma Aldrich), doping salt magnesium trifluoromethanesulfonate $\left(\mathrm{Mg}\left(\mathrm{CF}_{3} \mathrm{SO}_{3}\right)_{2}\right.$ or $\left.\mathrm{MgTf}\right)$ (Sigma Aldrich) were dried under vacuum for 2 days at 40 and $100{ }^{\circ} \mathrm{C}$ respectively. The nanochitosan was synthesized by ionotropic gelation method as described by literature earlier ${ }^{11,12}$. The filler nanochitosan was also dried under vacuum for $50{ }^{\circ} \mathrm{C}$ for 5 days before use. Nanocomposite polymer electrolyte were prepared dispersing appropriate amount of nanochitosan in polymer host and MgTf salt as displayed in Table 1 and hotpressed into films. Homogenous dispersive membranes were prepared by this procedure, which were dried under vacuum at $45^{\circ} \mathrm{C}$ for $24 \mathrm{~h}$ for further characterization.

Table 1. Composition of polymer, Magnesium salt and nanofiller

\begin{tabular}{cccc}
\hline Samples & PEO, Wt $\%$ & Mg salt, Wt \% & Nanofiller, Wt \% \\
\hline M1 & 95 & 5 & -- \\
M2 & 90 & 5 & 5 \\
M3 & 85 & 5 & 10 \\
M4 & 80 & 10 & 10 \\
M5 & 80 & 15 & 5 \\
M6 & 80 & 5 & 15 \\
\hline
\end{tabular}

The FTIR spectra were recorded by a JASCO 4100 (Japan) FTIR spectrometer with ATR accessory in the region of $400-4000 \mathrm{~cm}^{-1}$, with a signal average of 20 scans at a resolution of $4 \mathrm{~cm}^{-1}$. The morphology of the prepared samples was studied using $\mathrm{S}-3400 \mathrm{~N}$ scanning electron microscope hitachi make. The conductivity studies were carried out by Zahner IM6 (Germany) AC impedance analyzer with a sinal amplitude of $1 \mathrm{~V}$ and a 16 frequency points per decade. The thermal analysis of the films was examined by DSC analysis (Perkin Elmer thermal analyzer) in the temperature range from 20 to $200{ }^{\circ} \mathrm{C}$ at a scan rate of $20^{\circ} \mathrm{C} / \mathrm{min}$.

\section{Results and Discussion}

\section{FT-IR studies}

The qualitative aspects of infrared spectroscopy are one of the most powerful attributes of this diverse and versatile analytic technique. The dominant peaks of FTIR spectra of pure PEO, nanochitosan, PEO-MgTf complex M1 and M4 were identified and shown in Figure 1 (a-d). The peaks (Figure 1a) that appeared at 2888 and $2740 \mathrm{~cm}^{-1}$ in pure PEO correspond to symmetrical and asymmetrical stretching modes of $\mathrm{CH}_{2}-$ group. Moreover, the peaks 
showed at 1260,1240 and $1155 \mathrm{~cm}^{-1}$ are assigned to asymmetric $\mathrm{CH}_{2}$-twisting, symmetric $\mathrm{CH}_{2}$-twisting modes and $\mathrm{C}-\mathrm{O}-\mathrm{C}$ asymmetric stretching mode of pure PEO. It was observed from the Figure 1, the addition of magnesium salt and nanochitosan in polymer matrix made appropriate change in the FT-IR spectra of prepared polymer electrolytes. The $\mathrm{CH}_{2}$ wagging band that appeared at $1341 \mathrm{~cm}^{-1}$ for pure PEO shifted to $1349 \mathrm{~cm}^{-1}$ when nanochitosan was added to the PEO host polymer. The incorporation of nanochitosan in polymer matrix was confirmed by the appearance of a firm peak at $1646 \mathrm{~cm}^{-1}$ and $3458 \mathrm{~cm}^{-1}$ which was assigned to $\mathrm{NH}_{2}$ bending and $-\mathrm{OH}$ stretching (Figure 1 (b)). During complex formation, the above band shifted to $3450 \mathrm{~cm}^{-1}$ which was shown in (Figure 1 (d)). The bond length gets increased due to the decrease in wave number and thereafter complexation takes place. There were also some marked changes in C-O-C stretching mode in the PEO - MgTf complex system where the peak has shifted $4 \mathrm{~cm}^{-1}$ from $1094 \mathrm{~cm}^{-1}$. The symmetric stretching mode of $\mathrm{SO}_{3}$ at $1031 \mathrm{~cm}^{-1}$ arises due to the non-degenerate vibrational modes of $\mathrm{SO}_{3}$ which came from free triflate anions. This band shifted to $1029 \mathrm{~cm}^{-1}$ when nanochitosan filler was added to the PEO- salt complex indicating the formation of PEO- $\mathrm{Mg}\left(\mathrm{CF}_{3} \mathrm{SO}_{3}\right)_{2}$-nanochitosan composite polymer matrix. The band $1029 \mathrm{~cm}^{-1}$ completely disappears at higher concentration of nanochitosan thereby decreasing the number of mobile anions species and so the conductivity decreases.

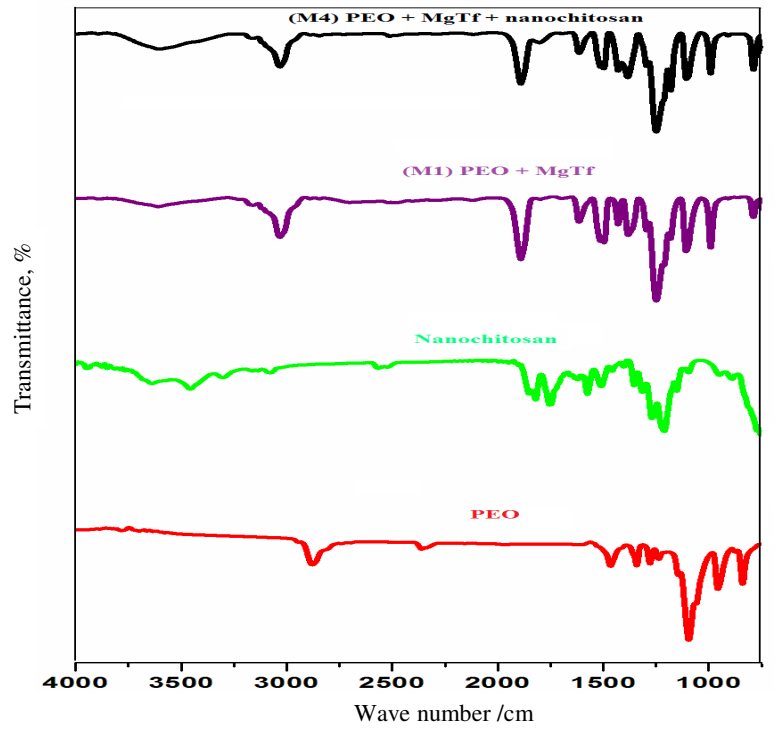

Figure 1. FT-IR spectra of (a) pure PEO, (b) nanochitosan, (c) M1 and (d) M4

\section{Ionic conductivity}

The variation of logarithm of ionic conductivity with respect to the temperature for the nanocomposite electrolyte film was depicted in Figure 2. The conductivity of PEO $-\mathrm{Mg}$ $(\mathrm{Tf})_{2}$ (M1) was found to be in the order of $10^{-5} \mathrm{Scm}^{-1}$ at $60{ }^{\circ} \mathrm{C}$. A gradual increase in conductivity was observed when a different weight percentage of nanochitosan was added to the complex which can be seen from M3 to M5. The polymer electrolyte sample M5 exhibited maximum ionic conductivity of $10^{-3} \mathrm{Scm}^{-1}$ when $10 \mathrm{wt} \%$ of nanochitosan and 15 wt $\%$ of magnesium salt were incorporated to the polymer matrix. The reason was the high density of mobile ions, availability of the vacant sites that can be accessed by the mobile ions and a good connectivity among the sites. According to Sundar et al. ${ }^{13}$ Lewis acid effectively 
decoordinates the $\mathrm{Mg}-\mathrm{O}$ bond, the Lewis acid sites on the surface of the filler interact with oxygen atoms of PEO and weaken the interaction between the oxygen atoms and $\mathrm{Mg}$ cations, and thus release more number of $\mathrm{Mg}$ cations which are necessary for conduction. In the present study the filler nanochitosan acted as cross-linking centers for the PEO segments, which lowered the reorganization tendency of polymer chain and in spite of its great number of amino groups the nanochitosan provided $\mathrm{Mg}^{2+}$ ions conducting pathways by carrying the strong $\mathrm{Mg}^{2+}$ ion at the filler surface and enhanced the ionic conductivity. On further addition of nanochitosan the ionic conductivity gets decreased for the sample M6. A similar effect occurred when the concentration of magnesium salt was added above $15 \mathrm{wt} \%$. The increase in salt concentration increases the viscosity of the solution and the film exhibit glue like nature. Therefore the conductivity can decrease due to the formation of neutral ion pairs when the distances between the dissociated ions become less ${ }^{14}$ i.e. due to aggregation of immobile ion species.

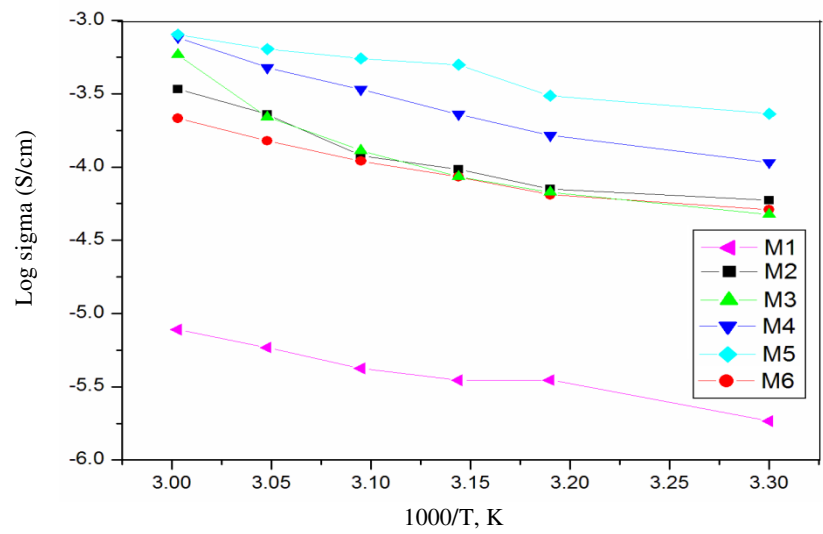

Figure 2. The variation of ionic conductivity as a function of temperature for nanocomposite electrolyte system

\section{Morphological studies}

The Figures 3 (a) \& (b) shows the SEM image of M1 and M4. It was quite observed from the Figure 3 (a), looks multi pore shape spherulites which was due to the addition of magnesium salt in the polymer host. The film also showed rough and uneven surface morphology. The implantation of nanofiller made significant changes in the morphology of polymer electrolytes which were distributed uniformly in the polymer - salt complex comparing to M1 filler free electrolyte film. It was attributed to the compatibility between the filler and the polymer host. Also the membrane texture was plain without pores which formed a rigid network.

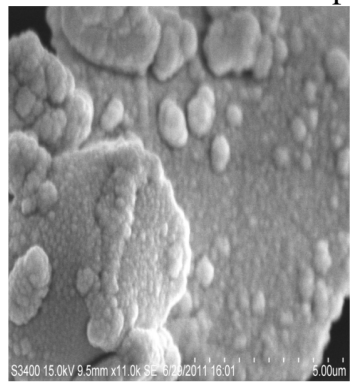

Figure 3. (a) SEM image of M1

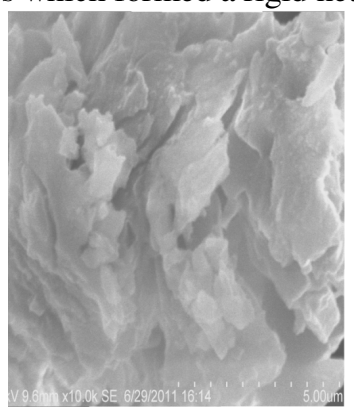

Figure 3. (b) SEM image of M5 


\section{Thermal studies}

\section{DSC analysis}

The DSC thermogram of polymer electrolyte samples M1, M4 and M5 were shown in Figure 4. As reported in the literature ${ }^{15}$ the endothermic peak at $66.1{ }^{\circ} \mathrm{C}$ corresponds to semicrystalline amorphous phase transition or melting temperature $T_{m}$ of pure PEO. In the present study when PEO was complexed with $\mathrm{Mg}$ salt and nanofiller, the melting temperature $\mathrm{T}_{\mathrm{m}}$ substantially decreased gradually and broaden the crystalline peak. Hence the crystalline texture of the PEO complex was affected due to the addition of ionic salt and nanochitosan. The dispersion of chitosan nanoparticles introduced the flexibility in polymer chains in delinking the temporary cross-linked $\mathrm{Mg}$-O bond and thereby increasing the mobility of $\mathrm{Mg}^{2+}$ ions along the segmental mobility of PEO chains. These results are in accordance with the result repoted by Hashmi et al., ${ }^{15}$.

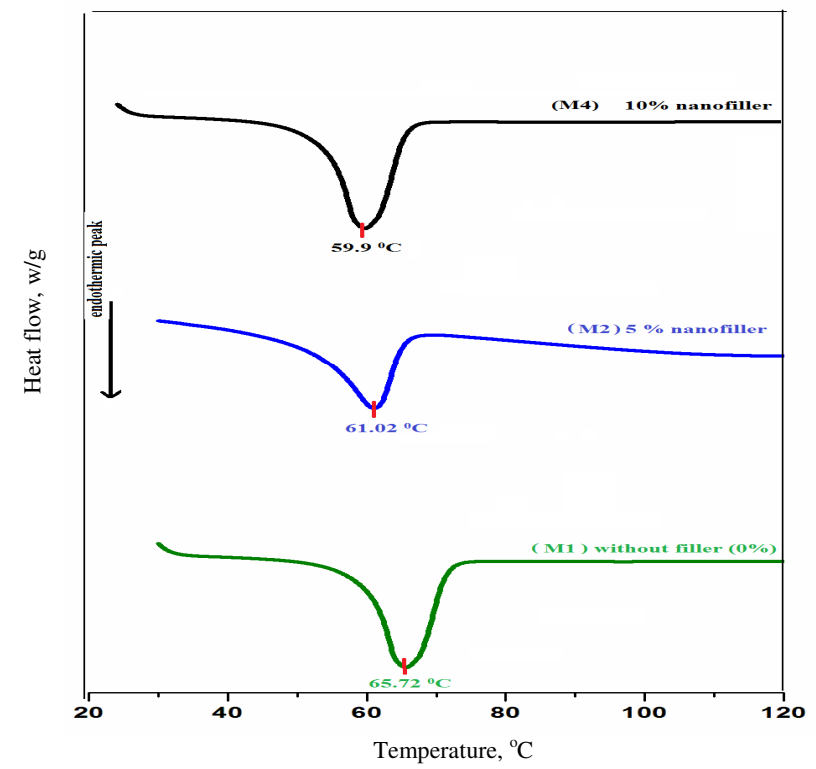

Figure 4. DSC thermogram of M1 (filler free electrolyte), M4 and M5 (filler-incorporated electrolyte)

\section{Conclusion}

In the present work the effect of implantation of nanochitosan in the polymer electrolyte had been studied. The occurrence of complexation between PEO - $\mathrm{Mg}\left(\mathrm{CF}_{3} \mathrm{SO}_{3}\right)_{2}$ - nanochitosan was revealed and the interaction between them was confirmed by FT-IR analysis. The decrease in crystalline temperature with increase in filler content (as well as increase in amorphicity) was confirmed by DSC study. The ionic conductivity measurement indicated that the conductivity increases with increase in filler content up to $10 \mathrm{wt} \%$ beyond that it decreases gradually. The maximum ionic conductivity was found to be in the order of 10-3.1 for sample M5 at $60{ }^{\circ} \mathrm{C}$.

\section{References}

1 Sheha E, Solid State Ionics, 2009, 180, 1575. 
2 Girish Kumar G and Munichandraiah N, J Power Sources, 2001, 102, 46.

3 Girish Kumar G and Munichandraiah N, J Power Sources, 2000, 91, 157-160.

4 Shoichiro Ikeda, Yoichi Mori, Yuri Furuhashi and Hideki Masuda, Solid State Ionics, 1999, 121(1), 329-333.

5 Pandey G P, Hashmi S A and Agarwal R C, Solid State Ionics, 2008, 179, 543.

6 Aravindan V and Vickraman P, Eur Polym J., 2007, 43, 5121.

$7 \quad$ Ramesh S and Soon- Chien Lu, J Power Sources, 2008, 185, 1439.

8 Changyu Tang, Nanxi Chen, Qin Zhang, Ke Wang, Qiang Fu and Xinyan Zhang, Polym Degrad Stab., 2009, 94, 124.

$9 \quad$ Pradip Kumar Dutta, Joydeep Dutta and Tripathi V S, J Sci Ind Res., 2004, 63, 20-31.

10 Ying Wan, Katherine A M Crebar, Brant Peppley and Tam Bui V, Polymers, 2003, 44, 1057-1065.

11 Huang, Kuo-Shien; Sheu, Yea-Ru; Chao and In-Chun, Polym Plast Technol Eng., 2009, 48(12), 1239-1243.

12 Karuppasamy K, Thanikaikarasan S, Antony R, Balakumar S and Sahaya Shajan X, Ionics, 2012, DOI 10.1007/s11581-012-0678-z.

13 Sundar M and Selladurai S, Ionics, 2006, 12, 281.

14 Kadir M F Z, Majid S R and Arof A K, Electrochim Acta, 2010, 55, 1475-1482.

15 Yogesh Kumar, Hashmi S A and Pandey G P, Electrochim Acta, 2011, 56, 3864. 